\title{
Design de produto para ressocialização: Análises e alternativas sobre a venda ambulante
}

João Matheus de Barros Câmara;

Sâmio Lucas Pachêco Barbosa

Resumo: Este artigo discorre sobre um projeto de design de produto entre o curso de bacharelado em Design da Universidade Federal do Maranhão (UFMA) com a Cooperativa Social do Estado do Maranhão (COOSEMA), buscando analisar a venda ambulante da cidade de São Luís (MA) para inserir e ressocializar ex-detentos do sistema carcerário pelo mercado de trabalho e ações sociais. Foram realizadas pesquisas exploratórias, geração de ideias e prototipação de alternativas que facilitassem a geração de renda e responsabilidade social, através de metodologias de contextualização e criatividade em design de produto. $O$ estudo e experiências diretas com a cooperativa e comunidade local permitiram o desenvolvimento de um expositor, como alternativa às necessidades analisadas em entrevistas e registros, promovendo a reflexão sobre o papel solidário do design na sociedade, assim como a importância de ações e políticas públicas que auxiliem indivíduos em vulnerabilidade socioeconômica.

Palavras-Chave: criatividade; design;maranhão; ressocialização;venda ambulante 


\section{Introdução}

Em meio a diversos contextos e problemas mundiais, o design atua como uma área do conhecimento e vetor de transformações segundo necessidades e metas de territórios e sociedades, compreendendo culturas, leis e inovações para gerar debates, sistemas e produtos que assegurem inovação e qualidade de vida. Esta responsabilidade socioeconômica da área abrange desde questões da natureza até direitos e deveres dos cidadãos no Brasil, priorizando e oferecendo alternativas para preocupações mais recorrentes, pois como defende Sobral (2002), a preocupação social e ecológica no país assume proporções de política nacional, sendo mais que uma tendência.

É a partir de preocupações e problemas mais recorrentes que a sociedade e as instituições podem utilizar do design como auxílio. No ano de 2017, a Cooperativa Social do Estado do Maranhão (COOSEMA) identificou a ressocialização como uma questão a ser trabalhada para estimular solidariedade e assegurar dignidade a ex-detentos do sistema carcerário, visando diminuir o crescimento da criminalidade e do desemprego no Brasil, cenário que segundo Fernandes (2017) tem relação com a rejeição social e falta de oportunidades no mercado de trabalho, fazendo com que a taxa de reincidência de criminalidade chegue a até $70 \%$ no país.

Reconhecendo a realidade criminal e o papel do design como possível gerador de alternativas e soluções, a COOSEMA e a Universidade Federal do Maranhão (UFMA) se uniram em um projeto através do curso de bacharelado em Design, onde os estudantes praticaram os princípios de pesquisa, ensino e extensão para estudar o contexto da venda ambulante na cidade de São Luís - MA (atividade realizada e sugerida pela cooperativa para o trabalho), com o propósito de oferecer aos ex-detentos oportunidades de geração de renda em um nicho de mercado estratégico e gerenciado, promovendo e dinamizando o serviço através de um produto singular e efetivo, confortável aos usuários diretos e compreendido pelos consumidores locais.

\section{Estratégias do design para os desafios da ressocialização}

A proposta inicial do projeto despertou a reflexão sobre as atribuições e os alcances do design quanto a contribuir no cenário de vulnerabilidade socioeconômica de ex-detentos, e como o desenvolvimento de produtos, uma vertente da área criativa e conjunto de técnicas já praticadas no curso de Design da UFMA, poderia contribuir valorizando um direito constitucional e de política econômica que deve ser assegurado pelo Estado, pois como discorre Tavares (2008),

[...] na criação e aplicação de medidas de política econômica deverá o Estado preocupar-se em proporcionar o pleno emprego, ou seja, situação em que seja, na medida do possível, aproveitada pelo mercado a força de trabalho existente na sociedade (TAVARES, 2008, p. 30).

É importante reconhecer que assim como o Estado tem a obrigação de cumprir com seus deveres constitucionais, o design também possui o caráter de suprir necessidades em sua essência, e estas também abrangem as políticas públicas, neste caso, no aspecto emergencial de ressocialização. $\mathrm{O}$ design de produto surge então como análise e construção de alternativas para a venda ambulante como uma ideia, ciência social e compreensão efetiva da questão no território, pois como reforça Miranda (2002), os objetos produzidos pelo design são o resultado de valores e concepções sobre a cultura e a sociedade, análises e artefatos ligados ao homem e ao ambiente.

Desta forma, se torna necessário compreender a vivência e detalhes da venda ambulante na cidade de São Luís - MA através de trabalho em campo e pesquisas de referências nacionais relacionadas para a elaboração do produto, seguindo a imersão ideológica e criativa proveniente de visões e metas estabelecidas pelos envolvidos no projeto, assim como os desejos da cooperativa mesclados à realidade dos indivíduos em vulnerabilidade socioeconômica (ex-detentos). Assim, é possível produzir um formato de trabalho confortável, atraente, coordenado e que atende aos anseios da comunidade, em diversos locais de venda (avenidas, feiras, pontos e interiores de ônibus), reinserindo excluídos na sociedade e abrindo um campo de novas oportunidades.

Reconhecemos diante disto que o projeto de design não deve ser fruto da interpretação profissional ou acadêmica de uma necessidade para a construção de uma solução - neste caso um 
artefato - mas sim o resultado de uma cooperação de visões e opiniões dos atores sociais envolvidos, pois"conforme argumentaram Ruskin e Morris, o grande poder do designer de alterar a sociedade reside muito mais na forma das suas relações de trabalho do que nas formas que ele atribui a um determinado artefato". (DENIS, 2000, p. 77).

\section{Metodologia}

Para nortear o processo do projeto, os estudantes e professores de design estabeleceram diálogos iniciais com a COOSEMA para chegar ao objetivo de construir um equipamento de venda ambulante que atendesse às necessidades dos ex-detentos para a inserção no mercado, com ações na cidade de São Luís - MA. Decidiu-se então realizar pesquisas em campo, entrevistas com a cooperativa e vendedores ambulantes, análises de expositores (equipamentos de venda) em nível local e nacional, assim como ferramentas de criatividade e prototipação para a construção de um modelo de produto viável.

Como desenvolvimento do trabalho foram organizadas etapas utilizando metodologias de design de produto, para serem realizadas em um semestre letivo. Estas metodologias são: A identificação dos componentes do problema (MUNARI, 2008) do projeto e entendimento da legislação atuante; a análise de similares (BAXTER, 2008) em serviços e produtos de venda ambulante com a observação e pesquisa de produtos, experiências e opiniões públicas acerca do tema; a seleção do estado da arte (MUNARI, 2008) da venda ambulante como o melhor produto existente para inspiração e melhorias da alternativa a ser gerada; a análise de funções (AYRES, 2003) do estado da arte para facilitar o processo de criatividade (PAZMINO, 2015) em desenhos e ideias; a elaboração de requisitos necessários para a proposta final (PHILLIPS, 2008) e a prototipação (MUNARI, 2008) de modelo físico do produto com testes e opiniões da cooperativa.

O contato e convivência dos estudantes com a cooperativa e vendedores locais foram experiências cruciais para a efetividade de todas as etapas metodológicas, com a realização de registros em imagens e das comunicações sobre a rotina e equipamentos de trabalho, assim como as expectativas em relação às alternativas. Valoriza-se então a participação de todas as pessoas e seus contextos no projeto, pois como defende Kuyper (1995), o design não existe sem o contexto social e seus diversos indivíduos com seus muitos repertórios.

\section{Analisando diversidades e contextos da venda ambulante}

Para iniciar o desenvolvimento do design de produto visando oportunidades para ex-detentos na venda ambulante da cidade de São Luís - MA, foi necessário entender como a atividade acontece no contexto local e que tecnologias são utilizadas. Munari (2008) aborda as pesquisas iniciais sobre o tema de projeto como componentes do problema, que são dados e informações de observação sobre o ambiente, ações e indivíduos em relação a um serviço ou produto.

Os estudantes então puderam realizar um levantamento sobre o perfil e características de vendedores ambulantes na cidade e no país, online e em campo, obtendo um encaminhamento inicial da cooperativa sobre as expectativas em relação ao produto: Ser um produto arrendável junto a outros elementos de venda ambulante que seria transportado em turno diurno para locais de trabalho organizados com distribuição e controle de atividades, comportando elementos sólidos, líquidos ou variados, chamando a atenção dos consumidores e promovendo renda extra, para ser usado preferencialmente por homens.

Este levantamento foi realizado com 34 vendedores e 30 consumidores em diversos locais de São Luís (praças, avenidas, ônibus, ruas) com pessoas de 18-55 anos, no período de 22/09/2017 a $17 / 10 / 2017$. Nesta abordagem presencial, foramquestionadas a todos quais as opiniões e expectativas em relação à venda ambulante, e após a reunião de respostas, foram sintetizadas as necessidades dos entrevistados. Os vendedores ambulantes expressaram a necessidade de um equipamento confortável, dinâmico, atrativo e que pudesse permitir visualização sucinta e rápida de produtos a serem vendidos aos consumidores, e os consumidores demonstraram necessidade por uma venda ambulante higiênica e que não fosse invasiva em abordagem.

Nesta etapa também foi necessário identificar questões de legislação estadual e as exigências sanitárias, por se tratar de um serviço com a possibilidade da venda de alimentos. Constatou-se que os 
vendedores ambulantes de alimentos que estejam na legalidade precisam apenas de um alvará de funcionamento, que é concedido pelas prefeituras, diferentemente dos estabelecimentos fixos, que é exigido o alvará da Vigilância Sanitária.

Também foi reconhecido que existem alternativas para a capacitação de vendedores ambulantes, como cursos organizados e ministrados pelo serviço de alimentação, por instituições terceirizadas e por instituições de fomento ao setor produtivo, como o Serviço Brasileiro de Apoio às Micro e Pequenas Empresas (SEBRAE). Os estudantes também puderam observar ao longo da pesquisa que algumas secretarias em conjunto com os órgãos de vigilância sanitária tiveram a iniciativa de tornar a figura e o ofício do ambulante menos negativo para a sociedade, tomando medidas que tiram o vendedor e seu produto da ilegalidade e da margem da insegurança.

\section{Identificação e transformação de alternativas: seleções e criatividade}

Após a contextualização dos aspectos mais importantes sobre a venda ambulante na cidade e no país, os estudantes selecionaram os equipamentos e vendedores mais frequentes vistos em campo para um melhor detalhamento nas ferramentas posteriores de design, ação definida por Baxter (2008) como uma análise de similares. Esta análise foi representada por um painel horizontal (ver imagem 1) com os expositores mais utilizados pelos trabalhadores, contendo as categorias de venda.

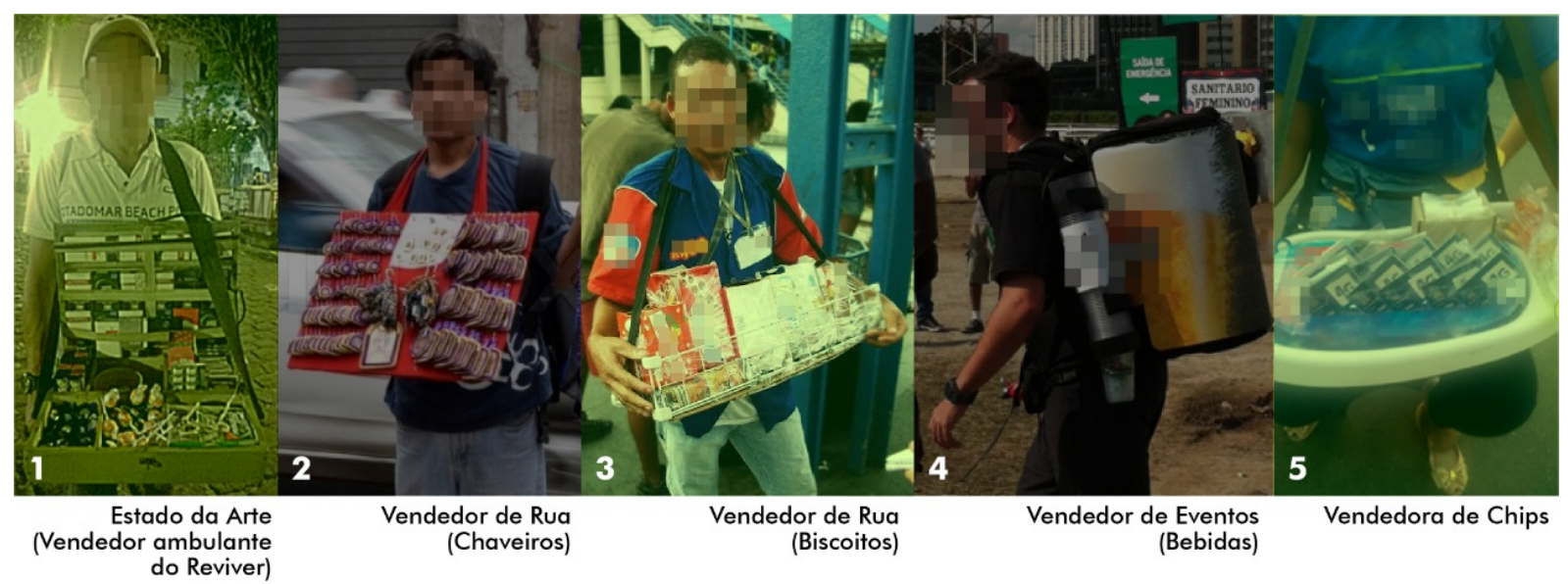

Imagem 1: Análise de similares. Dentre os diversos equipamentos utilizados na venda ambulante em São Luís -

MA, o destacado no registro 1 apresentou-se com mais frequência durante a pesquisa de campo, por isso, foi selecionado como o estado da arte, a maior referência de produto dentro do tema para o projeto.

Fonte: Os autores, 2017.

A identificação do melhor e mais frequente equipamento segundo as observações e diálogos em pesquisa de campo, este referido pelos vendedores como "caixa de ombro", pode ser utilizada como o estado da arte no tema, definidopor Munari(2008) como modelo de referência para o desenvolvimento do produto a inovar e solucionar a necessidade com mais efetividade. Este expositor (ver imagem 2) foi escolhido não apenas por ser o equipamento hegemônico da cidade de São Luís na venda ambulante, mas por também despertar o maior interesse entre os trabalhadores da área, por ser aparentemente prático e possuir capacidade e movimentação efetivas também de acordo com o usuário. A partir dessa escolha e das informações antes obtidas pela análise os estudantes realizaram uma representação gráfica (ver imagem 3) sobre a estrutura e compartimentos do estado da arte, para realizarem a análise das funções e detalhes que irão facilitar o redesign do produto. 

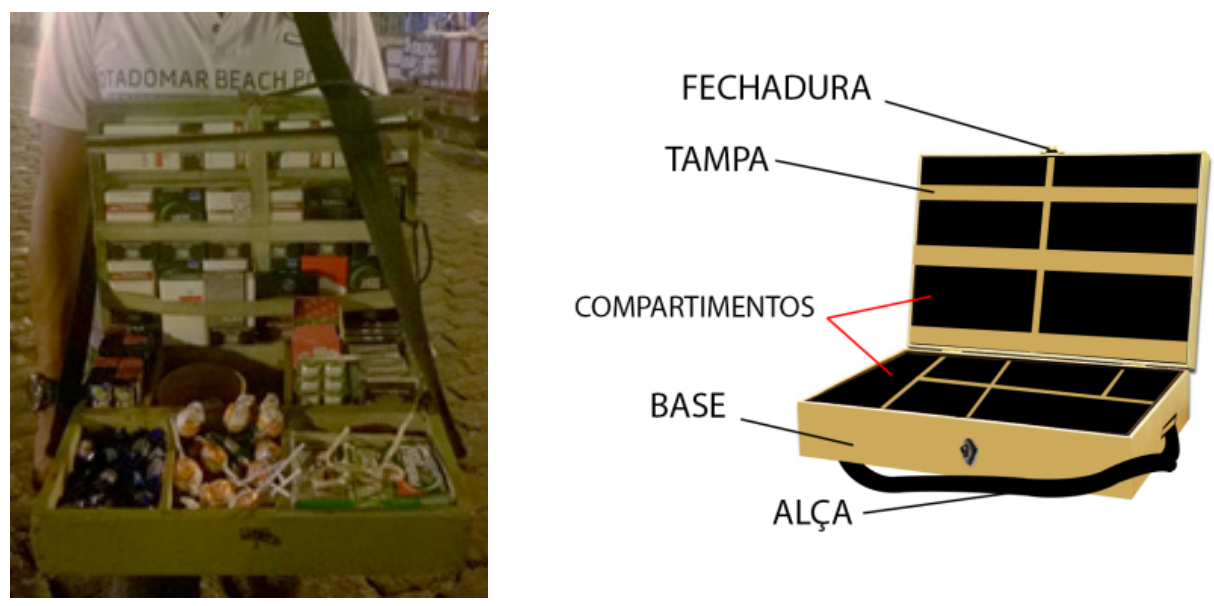

Imagens 2 e 3: Registro do estado da arte dos expositores de venda ambulante em São Luís - MA e representação gráfica com detalhes da estrutura.

Fonte: Os autores, 2017.

Após o aprofundamento sobre a estrutura do estado da arte, foi realizada a análise da função do expositor (ver imagem 4), as quais são categorizadas e esquematizadas informações que vão gerar pontos positivos a serem reutilizados e preservados, e pontos negativos a serem corrigidos, características que segundo Ayres (2003) permitem com que o designer entenda o potencial e limite do produto para construir alternativas possíveis e mais adequadas. Desta forma são refletidas as funções essenciais, técnicas e de usoque vão inspirar e trazer soluções para o novo produto.

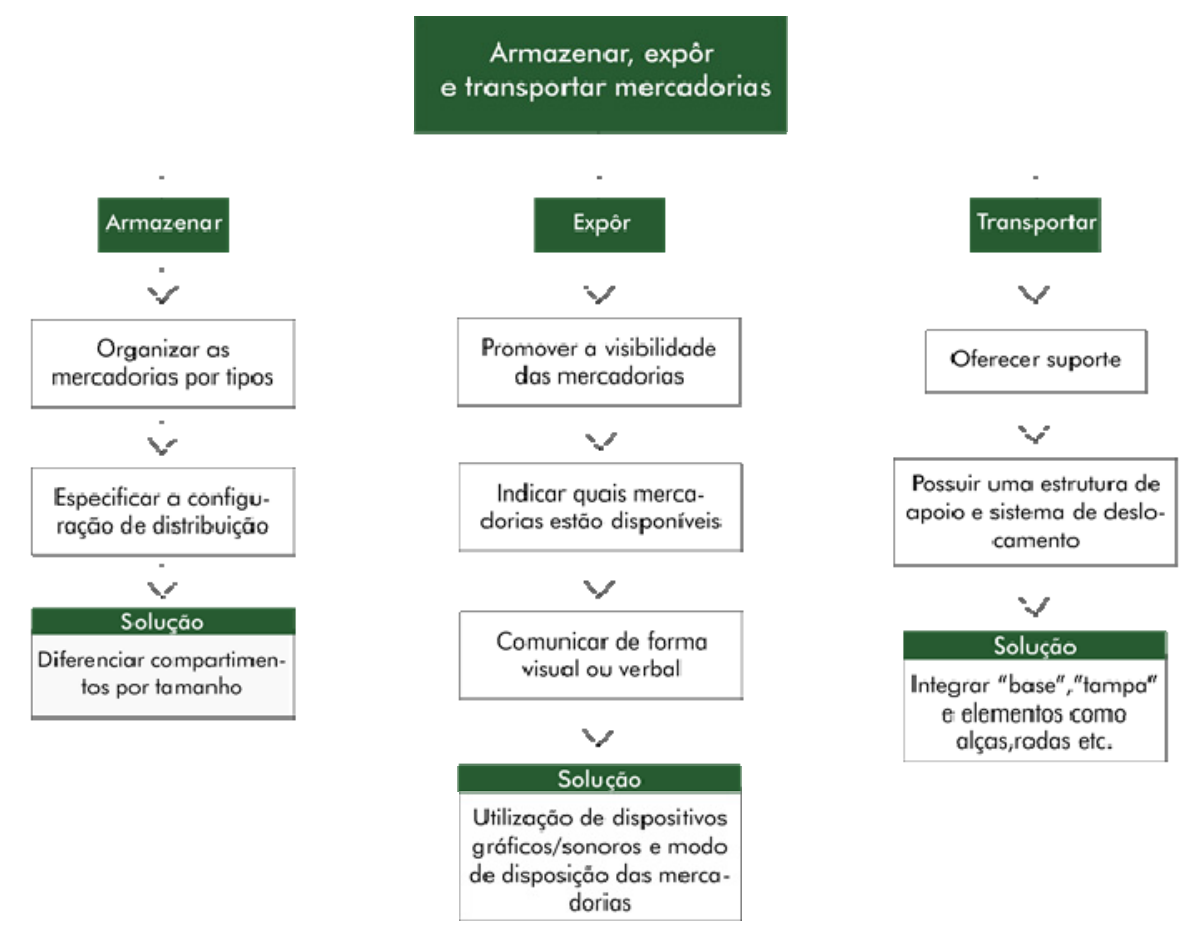

Imagem 4: Análise de funções essenciais do estado da arte.

Fonte: Os autores, 2017, adaptado de Ayres (2003).

Através do esquema são obtidos os primeiros caminhos técnicos a serem preservados no protótipo final, as soluções. Estas são discutidas entre os envolvidos no projeto, e geram uma análise paramétrica definida por Baxter (2011) como a consolidação de metas para a prototipação. As metas definidas após discussão foram: usar material de revestimento liso, resistente, impermeável,atóxico e de fácil limpeza; acabamento que evite desgaste à umidade e sujeira; não permitir cantos vivos; usar 
material de fácil manutenção; usar material mais leve; utilizar sistema de fechadura e mecanismo de sustentação da tampa (se aplicável); não utilizar pregos; usar material mais poroso, anatômico ou comum em produtos que são acomodados nos ombros; aumentar espessura; unir diferentes tipos de material e utilizar uniões que permitam maior dinamismo de organização e configuração dos compartimentos internos.

Além da análise paramétrica, foi realizada uma lista de requisitos obrigatórios através de tópicos sobre estrutura, uso e técnica, definidos por Phillips (2008) como questões a serem consideradas na prototipação. Estes requisitos foram: o equipamento deve armazenar e conservar os alimentos industrializados adequadamente (estrutura); sistema de acomodação cruzada em quatro pontos (uso) e estrutura adequada ao movimento (uso).Após a organização das informações obtidas em etapas anteriores, a equipe foi alinhada mais uma vez à realidade e problemática do equipamento de venda ambulante, sintetizando os problemas para trabalharcriativamente.

$\mathrm{Na}$ fase criativa, que precede o protótipo, os estudantes realizaram inicialmente um brainstorming de desenhos (ver imagem 5) usando todas as informações e requisitos estudados. Pazmino (2015) descreve essa técnica como a organização desenhada de ideias por cada indivíduo da equipe até o esgotamento de possibilidades, neste caso sobre o equipamento de venda ambulante. Depois de um tempo (10 minutos, por exemplo) se houver dificuldade, os integrantes podem olhar para os desenhos dos outros e preparar seus materiais para novas técnicas de criatividade.

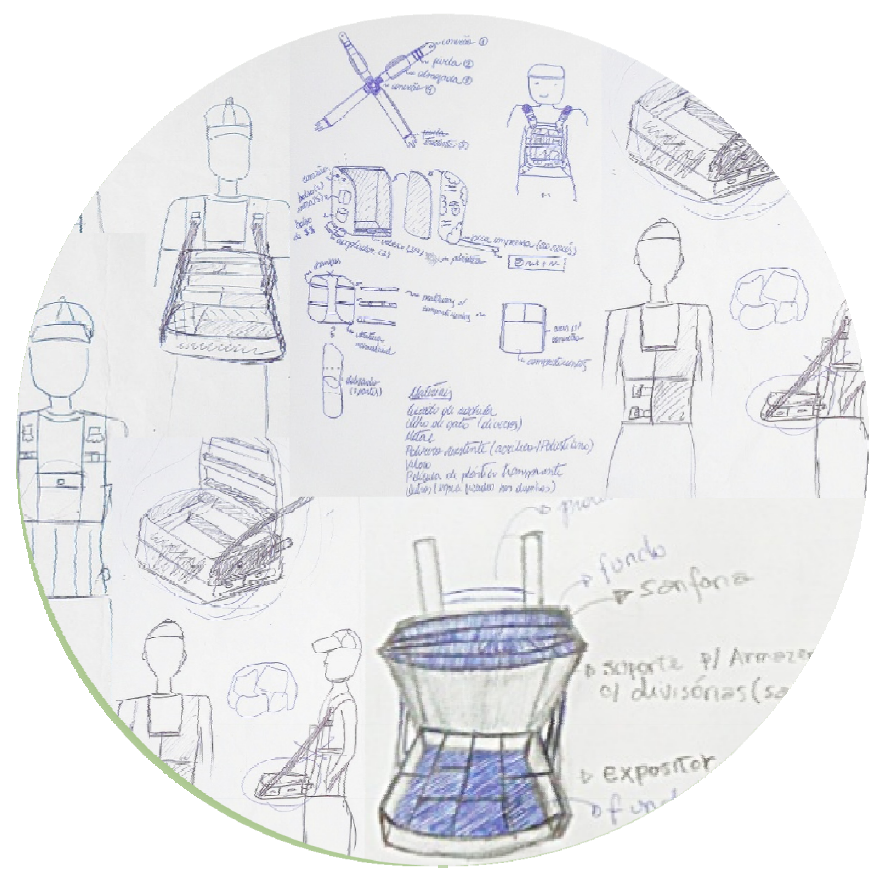

Imagem 5: Conjunto de desenhos criativos dos estudantes no brainstorming. Fonte: Os autores, 2017.

A segunda técnica de criatividade utilizada no projeto foi o Brainstorming 635, que consiste em um formulário onde cada estudante desenvolveu três sugestões desenhadas em turnos de 5 minutos, continuando a proposta dos outros em um ciclo de ideias. É muito importante para a concepção estrutural do equipamento de venda ambulante, e as melhores ideias (ver imagem 6) segundo o grupo são selecionadas para gerar o desenho de construção para o protótipo. 

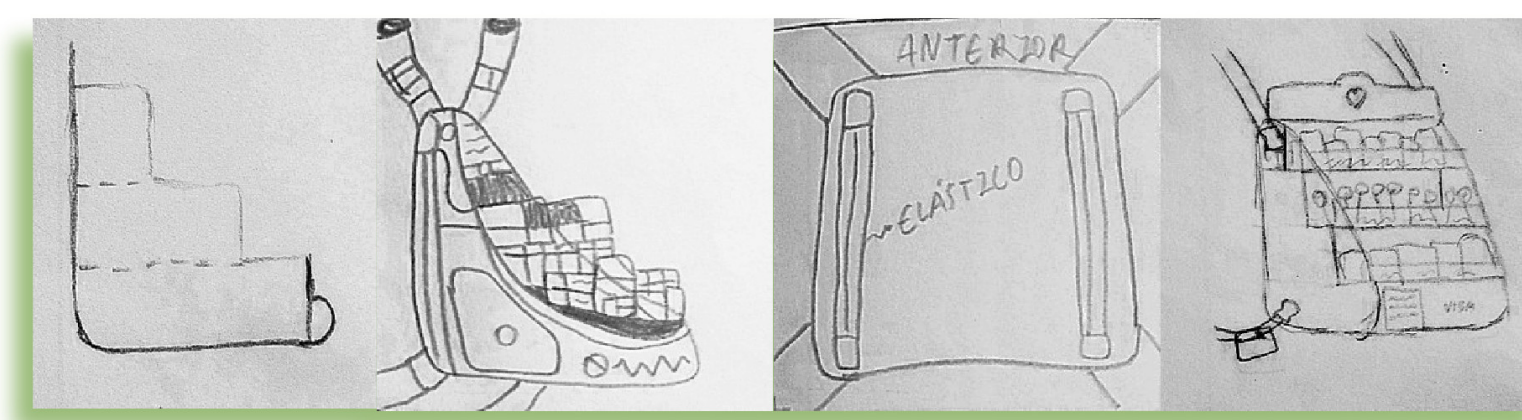

Imagem 6: Conjunto de desenhos selecionados para futura prototipação dentro da série produzida na técnica brainstorming 635 .

Fonte: Os autores, 2017.

O desenho de construção (ver imagem 7) foi realizado segundo as melhores ideias na criatividade e questões técnicas definidas nas etapas anteriores. $\mathrm{O}$ desenvolvimento dos detalhes em formas e cores também foi inspirado através dos dados de pesquisa e de campo, transformando os anseios e perspectivas dos vendedores em recursos gráficos.
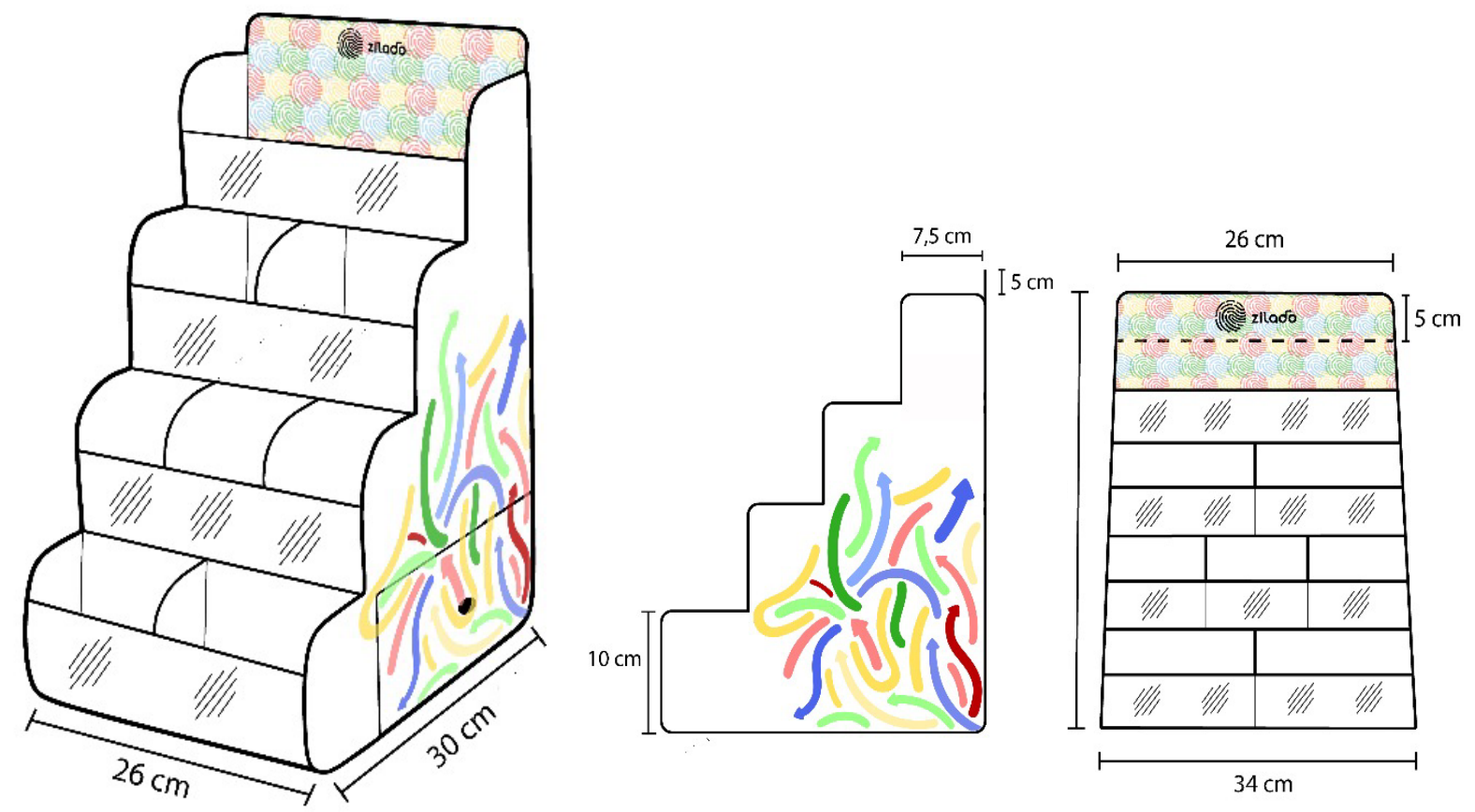

Imagem 7: Desenho de construção para o protótipo.

Fonte: Os autores, 2017.

Com a definição do desenho, os estudantes conseguiram construir um modelo físico para realizar testes iniciais (ver imagem 8), com materiais alternativos e leves. Após a construção são realizados os primeiros registros, movimentações e interações com o protótipo, para analisar o tamanho, formas e problemas a serem corrigidos. 

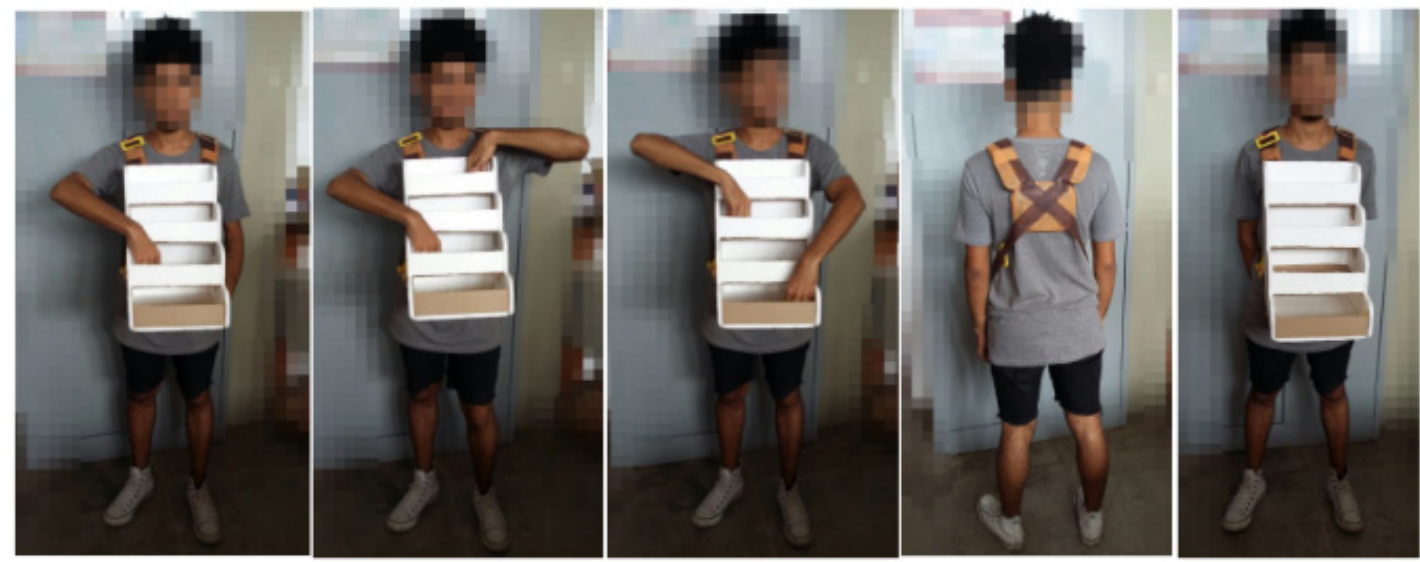

Imagem 8: Teste do primeiro protótipo.

Fonte: Os autores, 2017.

Após o teste do primeiro protótipo, os integrantes do projeto construíram o protótipo final com materiais similares ao produto almejado. Inicia-se então o teste final, a verificação da performance do produto (ver imagem 9), momento que Munari (2008) define como a observação e análise de eficácia, satisfação e eficiência entre o usuário e o equipamento.O teste foi realizado em cinco etapas e se concentrou: na identificação e organização dos compartimentos, composta pela tarefa de inserir as mercadorias em compartimentos diferentes do equipamento; nas alças e carcaça do equipamento, que foi realizada por meio das seguintes tarefas: passar o espaço entre as duas alças superiores pela cabeça e conectar cada encaixe inferior nos conectores inferiores da parte traseira do equipamento, ajustar o tamanho das alças pelas fivelas e posicionar o equipamento junto ao tronco; na movimentação do usuário com o equipamento, que foi realizada por meio da seguinte tarefa: ir e voltar entre dois pontos do laboratório com o equipamento; no alcance e movimentação em relação aos produtos nos compartimentos, que foi realizada através de simulações de venda e na retirada do equipamento do corpo e dos produtos nos compartimentos.
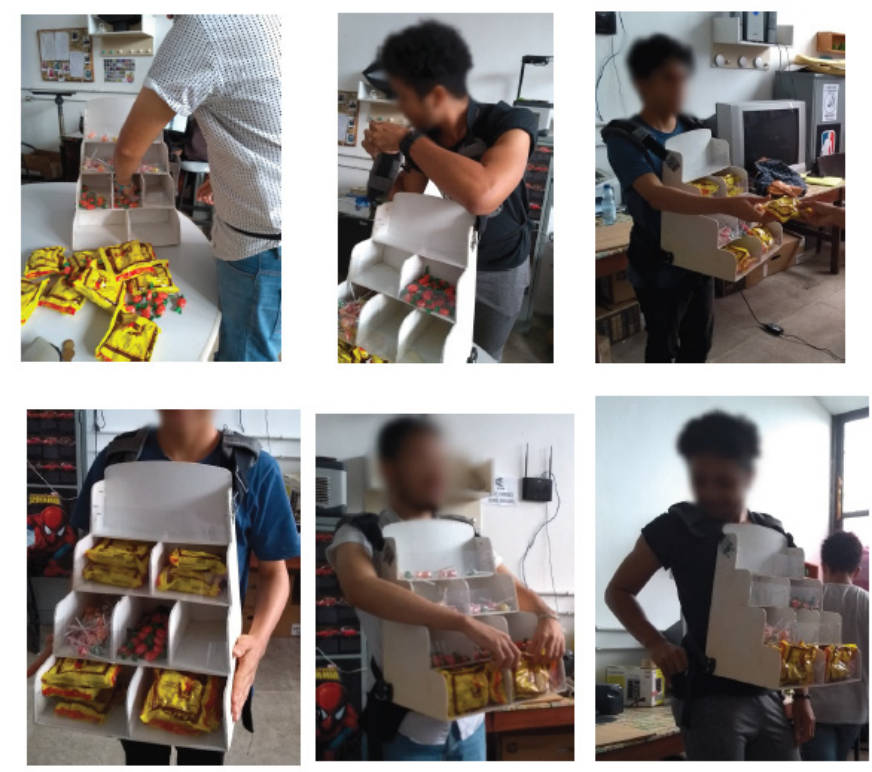

Imagem 9: Verificação do protótipo final.

Fonte: Os autores, 2017.

Com o teste, foi possível perceber que mesmo utilizando diversas ferramentas em design de produto ainda é possível identificar pontos a serem corrigidos no protótipo para serem finalizados no produto final. Como pontos positivos do expositor foi verificado que o equipamento é leve, se adequaconfortavelmente ao corpo e permite uma boa visualização das mercadorias, além do seu 
formato que permite uma melhor visibilidade das mercadorias para osusuários;e como pontos negativos reconhecemos que as alças não são auto ajustáveis, pois apresentaram dificuldade de visão dos conectores inferiores e dacaixa e oscompartimentos do segundo andar possuíram uma profundidade que causou desconforto ao usuário direto quando o mesmo precisou alcançar alguma mercadoria. Apesar das verificações finais, o produto se mostrou bastante efetivo para a cooperativa, alcançando os objetivos esperados no início do processo.

\section{Conclusão}

Estudar e construir alternativas de design de produto para ressocialização é um desafio que condiciona instituições e a própria sociedade a refletir sobre vulnerabilidades socioeconômicas, o papel do Estado no cumprimento da constituição e a união de saberes e opiniões públicas no desenvolvimento de serviços e equipamentos que supram a necessidade por trabalhos dignos.

A condução da pesquisa consolida a importância de alinhar inovação à realidade de territórios, onde a criminalidade se mostra como um problema que deve ser discutido e não invisibilizado, pois através da educação e criatividade é possível verificar caminhos e tecnologias que combatam as desigualdades socioeconômicas.

O projeto correspondeu às possibilidades de ensino, pesquisa e extensão da universidade e à identificação da venda ambulante como uma atividade de geração de renda aos ex-detentos do Estado, coordenados pela cooperativa. Levando em consideração os potenciais teóricos e práticos dos estudantes do curso deDesign, os envolvidos entraram em consenso para a produção de uma alternativa de produto com a utilização de materiais e processos sustentáveis e acessíveis às condições da COOSEMA e aos desejos dos vendedores ambulantes de São Luís-MA assim como aos exdetentos cooperados, que necessitam de mais atitudes solidárias como esta na promoção de qualidade de vida e segurança no Brasil.

\section{Product design for resocialization: Analysis and alternatives about street vending}

Abstract: This article discusses a product design project between the Bachelor of Design course at the Federal University of Maranhão (UFMA) with the Social Cooperative of the State of Maranhão (COOSEMA), seeking to analyze the street vending of the city of São Luís to insert and to resocialize former prisoners of the prison system through the labor market and social actions. Exploratory research, generation of ideas and prototyping of alternatives were carried out to facilitate the generation of income and social responsibility, through methodologies of contextualization and creativity in product design. The study and direct experiences with the cooperative and the local community allowed the development of an exhibitor, as an alternative to the needs analyzed in interviews and records, promoting reflection on the solidary role of design in society, as well as the importance of public attitudes and policies that assist individuals in socioeconomic vulnerability.

Keywords: creativity; design;maranhão; resocialization; street vending

\section{Referências bibliográficas}

AYRES, Érico. Metodologia do projeto em Design de produto. São Paulo: Santa Clara, 2003.

BAXTER, Mike. Projeto de Produto: guia prático para o projeto de novos produtos. São Paulo: Edgard Blucher, 2000.

DENIS, Rafael Cardoso. Uma introdução à história do design. São Paulo: Edgard Blücher, 2000. 
FERNANDES, Rodrigo. Brasil: Reincidência de até 70\%. Disponível em:

http://institutoavantebrasil.com.br/brasil-reincidencia-de-ate-70/. Acesso em 02 ago. 2020.

KUYPER, Jan. Design é uma arte social. In: Revista da aldeia humana. Florianópolis: SENAI, 1995.

MIRANDA, Danilo S. de. A cultura do design. In: Um olhar sobre o design Brasileiro. São Paulo: Objeto Brasil; Instituto Uniemp; Imprensa Oficial do Estado, 2002.

MUNARI, Bruno. Das coisas nascem as coisas. 2. ed. São Paulo: Martins Fontes, 2008.

PAZMINO, Ana Veronica. Como se cria: 40 métodos para Design de produtos. São Paulo: Edgard Blucher, 2015.

PHILLIPS, Peter L. Briefing: A gestão do projeto de Design. São Paulo: Edgard Blucher, 2007.

SOBRAL, Sandra. Tendências do design. In: Um olhar sobre o design Brasileiro. São Paulo: Objeto Brasil; Instituto Uniemp; Imprensa Oficial do Estado, 2002.

TAVARES, André Ramos. 1988-2008: vinte anos da constituição cidadã. São Paulo: Imesp, 2008. 